\title{
Measuring Surgical Quality: What's the Role of Provider Volume?
}

\author{
Justin B. Dimick, M.D., ${ }^{1}$ John D. Birkmeyer, M.D., ${ }^{2}$ Gilbert R. Upchurch Jr, M.D. ${ }^{2}$ \\ ${ }^{1}$ Center for the Evaluative Clinical Sciences, Dartmouth Medical School, Hanover, New Hampshire, USA \\ ${ }^{2}$ Michigan Surgical Collaborative for Outcomes Research and Evaluation (M-SCORE), Department of Surgery, University of Michigan \\ Medical Center, Ann Arbor, Michigan 48109, USA
}

Published Online: September 8, 2005

\begin{abstract}
Although not ideal for all situations, provider volume is particularly suited for measuring surgical quality in certain contexts. Specifically, we believe that for uncommon operations with a strong volumesoutcome effect, provider volume may be the most informative performance measure. Because of the relative ease of determining provider volume, it will continue to be used in value-based purchasing and public reporting efforts. With increasing momentum from outside the profession of surgery, it is particularly important for surgeons to participate in making decisions regarding situations where volume may be an appropriate measure of quality.
\end{abstract}

Provider experience plays a large role in determining outcomes for many surgical procedures [1-3]. With three decades of research showing variations in mortality rates between high- and low-volume providers, it is surprising that until recently very little has been done to concentrate surgery in high-volume hospitals. Over the past few years, however, there has been increased interest in using provider volume as a measure of quality. For certain operations, existing health policy efforts are focused on selectively referring patients to high-volume hospitals [4].

Given the growing interest in this area, we sought to review the evidence linking hospital volume to outcomes, discuss new evidence regarding the importance of individual surgeon volume, and describe current health policy efforts that focus on using provider volume as a quality measure. We then considered the advantages and disadvantages of using provider volume to measure surgical quality.

\section{Hospital Volume and Mortality}

Two recent structured literature reviews provide a comprehensive picture of the large body of evidence linking volume to outcome $[1,2]$. In the first review, Dudley and colleagues identified all studies published over 10-year period (1988-1998) investigating hospital volume and mortality for numerous surgical and medical

Correspondence to: Gilbert R. Upchurch Jr, M.D., e-mail: riversu@ umich.edu conditions [2]. After excluding poor quality studies, 72 articles addressing 40 different procedures and diagnoses were identified. For the purposes of this review, we will limit the discussion to operations within vascular and general surgery. For vascular surgery, there were three operations represented (carotid endarterectomy, abdominal aneurysm repair, and lower extremity bypass) and 19 of 23 studies (83\%) showed a positive relationship between volume and outcome (16 were statistically significant and 3 showed a trend). Within general surgery, there were 10 operations represented, and 34 of $34(100 \%)$ studies showed a positive relationship between volume and outcome ( 28 were statistically significant and 6 showed a trend).

In the second review, Halm and colleagues identified volumeoutcome studies published over a 20-year period (1980-2000) [1]. Of 272 studies reviewed, 135 met the inclusion criteria that were based largely on methodogical rigor of the studies. We have abstracted the data for all studies relevant to vascular and general surgery (Table 1). In general, the results were similar to the previous review, with most studies showing a strong positive effect of increasing volume on improved mortality. In addition, this review included the magnitude of the effect (differences in mortality between high- and low-volume hospitals), which varied depending on the procedure. For instance, carotid endarterectomy and colon resection have very small effects, with some studies showing no effect, whereas for pancreatic and esophageal resection, almost all studies show an effect and the absolute difference in mortality are on the order of $12.0 \%-13.0 \%$ (Table 1 ).

Although these reviews provide a balanced overview of the existing literature, it is worth considering one individual study in more detail. In the largest and most comprehensive volumeoutcome study, Birkmeyer and colleagues investigated 14 operations in the U.S. Medicare population [3]. Consistent with the reviews cited above, they found a significant effect of volume on outcome for all the procedures. However, the strength of the relationship between hospital volume and mortality was also shown to vary extensively, depending on the specific operation. The absolute differences in operative mortality between the highest volume and the lowest volume hospitals ranged from $12.5 \%$ for pancreatic resection to $0.2 \%$ for carotid endarterectomy (Fig. 1). 
Table 1. Summary of articles examining associations between hospital volume and mortality for vascular and general surgery operations.

\begin{tabular}{|c|c|c|c|c|c|}
\hline Procedure & $\begin{array}{l}\text { Number of studies } \\
\text { (statistically significant) }\end{array}$ & $\begin{array}{l}\text { Median cases defining } \\
\text { low volume (range) }\end{array}$ & $\begin{array}{l}\text { Median cases } \\
\text { defining high } \\
\text { volume (range) }\end{array}$ & $\begin{array}{l}\text { Median average } \\
\text { mortality rate }\end{array}$ & $\begin{array}{l}\text { Median absolute } \\
\text { difference in mortality } \\
\text { for high vs low } \\
\text { volume (range) }\end{array}$ \\
\hline \multicolumn{6}{|l|}{ Vascular operations } \\
\hline Carotid endarterectomy & $15(7)$ & $10(5-50)$ & $50(21-100)$ & $1.8(0.9-2.3)$ & $0.4(-.05-1.8)$ \\
\hline $\begin{array}{l}\text { Elective abdominal } \\
\text { aneurysm repair }\end{array}$ & $8(7)$ & $12(3-31)$ & $36(12-433)$ & $7.5(3.8-7.6)$ & $3.3(1.1-11.6)$ \\
\hline $\begin{array}{l}\text { Ruptured abdominal aneurysm } \\
\text { repair }\end{array}$ & $8(2)$ & $9(2-10)$ & $20(5-50)$ & $49.8(40.0-63.2)$ & $7.9(1.5-18.7)$ \\
\hline $\begin{array}{l}\text { Lower extremity arterial bypass } \\
\text { General surgery operations }\end{array}$ & $2(1)$ & 13 and 20 & 32 and 100 & 3.1 and 3.8 & 1.1 and 1.4 \\
\hline Pancreatic resection & $10(9)$ & $5(1-22)$ & $20(3-200)$ & $9.7(5.8-12.9)$ & $13.0(3.0-17.9)$ \\
\hline Esophageal resection & $3(3)$ & $5(5-10)$ & $30(11-200)$ & $13.9(8.9-14.0)$ & $12.0(11.0-13.9)$ \\
\hline Breast cancer surgery & $1(1)$ & 10 & 151 & NA & $a$ \\
\hline Colorectal resection & $10(4)$ & $18(10-84)$ & $115(18-253)$ & $6.0(3.5-12.3)$ & $1.9(-1.2-9.7)$ \\
\hline Gastric resection & $3(1)$ & $10(5-15)$ & $63(15-201)$ & 10.9 & $6.5(4.0-7.1)$ \\
\hline
\end{tabular}

${ }^{\text {a }}$ Results were reported in terms of 5-year survival. In this study, patients in the lowest-volume hospitals had a $60 \%$ higher risk of death within 5 years than those at high-volume hospitals.

Source: Modified from Halm et al. [1]

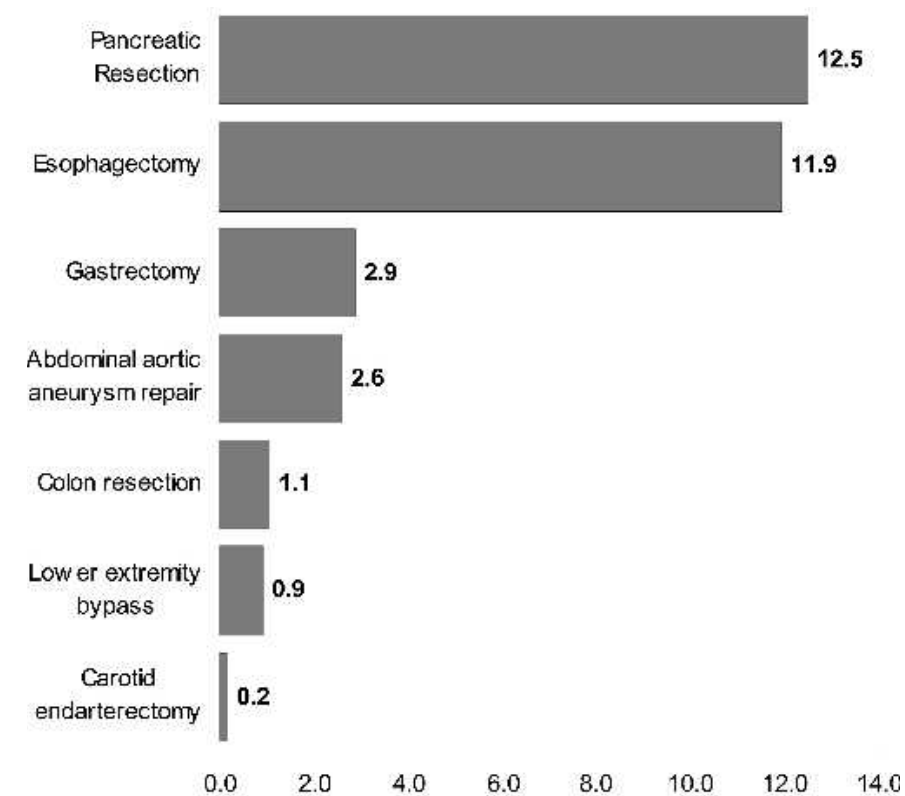

Absolute Difference in Mortality (\%) (very low vs. very high volume)

Fig. 1. Absolute mortality differences between very high and very low volume hospitals for general and vascular surgery. Based on national Medicare data and Birkmeyer et al. [2].

Most studies of the effect of volume on outcome are criticized because they are conducted using administrative data [1-3]. Compared to prospective, clinical data registries, administrative data sources have less clinical detail available for risk-adjustment. As a result, it is argued that differences in mortality rates between high- and low-volume hospitals may be due to residual differences in patient characteristics [5, 6]. There are two reasons why this scenario is unlikely. First, many studies using clinical data have also shown a significant effect of volume on outcome $[1,7,8]$. Second, the "null" volume-outcome investigations that use rigorous clinical risk-adjustment also show no effect without riskadjustment [6]. If the lack of a volume-outcome effect were due to more detailed clinical risk-adjustment, there would be a dif- ference in the unadjusted outcomes between high- and low-volume hospitals. The difference in unadjusted outcomes should disappear after taking into account the additional clinical variables. It is possible that the estimates of volume-outcome effects would be different using more detailed risk-adjustment, but there are no data to support the notion that the effects will disappear entirely.

Taking all this evidence into account, two important generalizations can be drawn. First, it is clear that hospital volume is important in determining operative mortality. The large numbers of studies coming to the same conclusion make this fact difficult to refute. Second, it is also clear that uncommon, high-risk cancer procedures (e.g., pancreatic and esophageal resection) have much larger effects than more common operations (e.g., colon resection and coronary artery bypass grafting). What is less clear is exactly how to translate this information into policy that helps patients and improves the overall quality of surgical care. We consider the strengths and limitations of using hospital volume as a quality indicator in a future section of this review.

Studying the relationship between hospital volume and mortality may be useful for reasons other than selective referral policies. High-volume hospitals are likely adhere to certain processes of care that lead to superior outcomes, but very few of these fine details of surgical care are known. Identifying process measures that contribute to variations in surgical outcomes will be a necessary step in improving the overall quality of surgical care. Indeed, for medical conditions, such as acute myocardial infarction, studies have shown that existing hospital-level variations in mortality are mediated through the appropriate use of aspirin and beta-blockers [9]. Although similar studies in surgical populations will help identify ways for hospitals to improve, it is not clear that even a complete inventory of these processes of care will raise low-volume hospitals to the same level of performance as highvolume hospitals.

\section{Surgeon Volume and Patient Mortality}

Largely because hospital volume is more easily determined, many previous studies have not considered the role of individual surgeon volume. In the review by Halm and colleagues, a much 


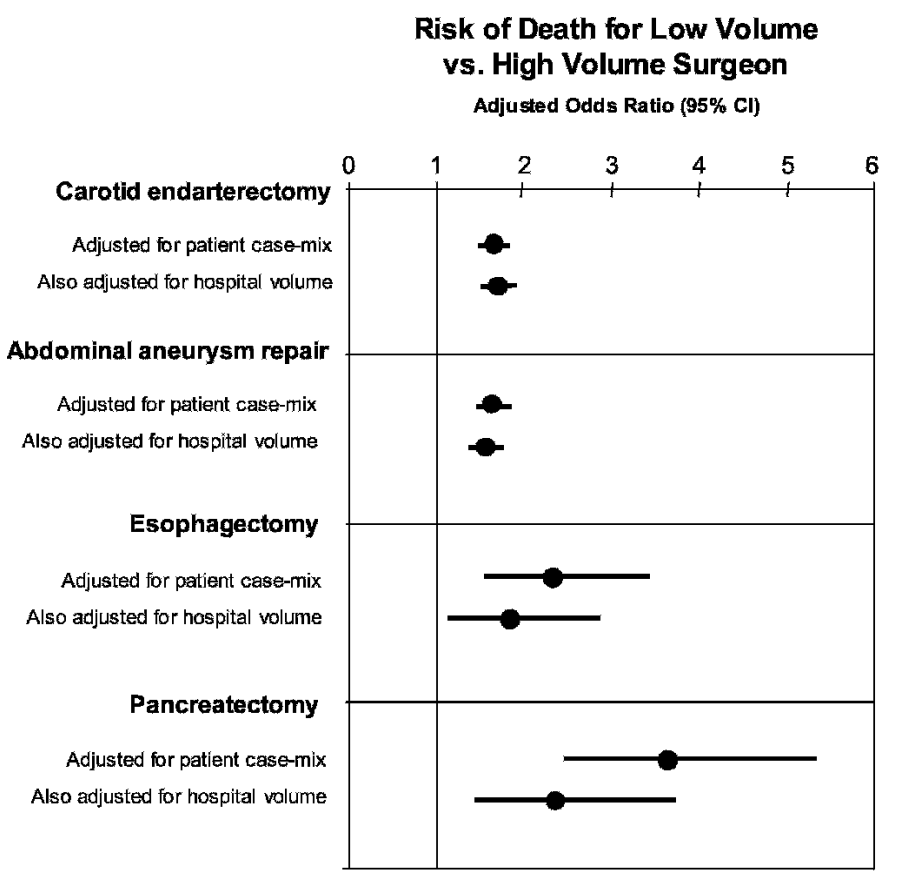

Fig. 2. Effect of surgeon volume on mortality before and after adjusting for hospital volume. From these analyses, the proportion of the surgeon volume effect attributable to hospital volume can be estimated. Data from the National Medicare database, modified from Birkmeyer et al. [10].

shorter list of studies investigated the impact of surgeon volume. For those operations where surgeon volume was considered, most also showed a significant effect on mortality [1]. Few of these studies, however, had sufficient sample size or used appropriate multi-level modeling methods to determine the relative impact of hospital and surgeon volume in contributing to low operative mortality.

In a recent study using the national Medicare population from 1998-1999, Birkmeyer and colleagues overcame many of the limitations of previous studies of surgeon volume and outcomes. The authors found that surgeon volume was a strong independent predictor of operative mortality for all eight operations considered [10]. Figure 2 shows the impact of surgeon volume on mortality for four general and vascular operations before and after adjusting for the effect of hospital volume. Interestingly, hospital volume accounted for a variable proportion of the observed surgeon volume effect. With carotid endarterectomy, for example, none of the effect is attributable to hospital volume. For other operations, hospital volume accounts for up to one half of the surgeon volume effect. This finding has strong face validity, since carotid endarterectomy requires few resources beyond the skill of the individual surgeon. In contrast, abdominal aortic aneurysm repair requires optimal functioning of a broad range of resources (e.g., anesthesia staff and intensive care units). Given the strong independent effect of individual surgeon volume on mortality, especially for certain operations, it is likely to play a larger role in future efforts to measure quality.

\section{Efforts to Incorporate Provider Volume into Health Policy}

Provider volume is currently at the center of health policy efforts aimed at improving the quality of surgical care. The theoretical goals of releasing quality information, such as provider volume, to the public are threefold: (1) patients will be able to choose the best hospitals; (2) payers will create incentives that direct patients to the best hospitals; and (3) providers will use the information to direct quality improvement activities. As a quality indicator, provider volume is most directly applicable to the first two of these objectives. But provider volume can also serve a useful role in quality improvement. If the processes of care that enable highvolume providers to have the best outcomes can be isolated ("best practices"), these can be exported to other settings and improve the care at all hospitals. However, the use of volume in this quality-improvement capacity has taken a back seat to the selective referral efforts.

Largely because hospital volume is easily determined from readily available administrative data, it is central to several public-reporting initiatives. Table 2 shows an illustrative but not exhaustive list of public reporting efforts that include hospital volume. Using national administrative databases, a growing number of proprietary Internet sites now provide hospital volume for many operations (e.g., Healthgrades.com). In addition, the Agency for Healthcare Research and Quality has included the hospital volume of several surgical procedures in their Inpatient Quality Indicators [11]. These quality indicators have subsequently been used by payers (e.g., Blue Cross Blue Shield in New York State) and state health organizations (e.g., Texas Inpatient Hospital Association) for public reporting of volume. However, despite the increasing availability of information on hospital volume, the public doesn't seem to be using it to help choose hospitals [12-14]. Future investigations should explore how patients go about choosing hospitals and try to determine why most ignore hospital report cards. Is it because they don't know about the report cards? Or is it because they prefer to go to a local hospital?

Another use of publicly available information on quality is gaining momentum: health care payers are seeking to selectively contract with providers based on the quality of care they provide (value-based purchasing). As the most visible of these efforts, the Leapfrog Group represents many large employers interested in creating incentives that result in directing more patients to the highest quality hospitals [4]. The Leapfrog Group's initial patient safety practices recommended selective referral to high-volume hospitals for five procedures: coronary artery bypass grafting, percutaneous coronary interventions, esophageal resection, abdominal aortic aneurysm repair, and carotid endarterectomy.

It should be noted that several recent changes have been made in the 2003 Leapfrog standards (Table 3). In the updated standards, carotid endarterectomy has been dropped from the list, largely because of the very small hospital volume effect. In contrast, pancreatic resection has been added because of many studies documenting a strong relationship between volume and outcomes. Also in the updated standards, there has been a shift toward incorporating more than volume standards. The use of perioperative beta-blockade (a process measure) has been added for abdominal aortic aneurysm repair. Hospitals must demonstrate that at least $80 \%$ of patients receive beta-blockers to be fully compliant. Also in the new standards, full compliance for coronary artery bypass grafting requires demonstrating low risk-adjusted mortality rates either in those states with existing public reporting efforts (NY, NJ, PA, CA) or through the use of the Society of Thoracic Surgeons database. 
Table 2. Publicly available information on surgical volume.

\begin{tabular}{llll}
\hline Name of Source & Sponsor & Area represented & Source of data \\
\hline Health Grades & Proprietary & United States & National Medicare database \\
Leapfrog Group & Business roundtable & United States & Self-reported by hospital \\
Hospital Quality Reports & BlueCross BlueShield & Upstate New York & State hospital discharge database \\
Indicators of Inpatient Care in & Texas Health Care & Texas & State hospital discharge database \\
Texas Hospitals, 2000 & Information Council & Pennsylvania & State hospital discharge database \\
Pennsylvania Hospital Performance & Pennsylvania Health Care & & \\
Reports & Cost Containment Council & & \\
\hline
\end{tabular}

Table 3. Leapfrog Group evidence-based hospital referral: comparison of previous and updated (2003) standards for full compliance.

\begin{tabular}{lll}
\hline Procedure & Previous Leapfrog standards (2000) & Updated Leapfrog standards (2003) \\
\hline $\begin{array}{l}\text { Pancreatic resection } \\
\text { Carotid endarterectomy }\end{array}$ & Not included & Hospital volume $\geq 11 /$ year \\
Esophagectomy & Hospital volume $\geq 100 /$ year & Dropped because of small volume-outcome effect \\
$\begin{array}{l}\text { Elective abdominal aneurysm } \\
\text { repair }\end{array}$ & Hospital volume $\geq 7 /$ year & Hospital volume $\geq 13 /$ year \\
$\begin{array}{l}\text { Coronary artery bypass grafting } \\
\text { Hospital volume } \geq 30 / \text { year }\end{array}$ & Hospital volume $\geq 500 /$ year & $\begin{array}{l}\text { Hospital volume } \geq 50 / \text { year \& perioperative } \\
\text { beta-blockers for more than } 80 \% \text { of patients }\end{array}$ \\
$\begin{array}{l}\text { Combination of risk-adjusted mortality rates and hospital volume } \\
\text { interventions }\end{array}$ & Hospital volume $\geq 400 /$ year & $\begin{array}{l}(\geq 40 / \text { year) } \\
\text { Combination of risk-adjusted mortality rates and hospital volume } \\
(\geq 400 / \text { year) }\end{array}$ \\
\hline
\end{tabular}

${ }^{a} \mathrm{NY}$, NJ, PA, CA have prospective outcomes registries for coronary artery bypass grafting, and full compliance requires that a hospital be in the lowest quartile of mortality. For other states, hospitals must take part in the Society of Thoracic Surgeons database and have mortality rates below the national average as well as meet the volume standard.

${ }^{\mathrm{b}}$ Similar to coronary bypass, except only NY State has a prospective outcomes registry for percutaneous coronary interventions. Hospitals outside of NY must take part in the American College of Cardiology registry, they must have mortality rates lower than average, and they must meet the volume standard.

\section{Strengths and Weaknesses of Provider Volume as a Quality Indicator}

Using provider volume as a proxy for quality has several advantages compared to other approaches. First, volume is easily determined from readily available data sources. In contrast, direct outcomes measurement requires detailed clinical data that are not widely available. Second, provider volume is meaningful to patients. Unlike many complex quality measures used in some hospital report cards, patients can grasp the value of "experience" with a specific procedure. Finally, another advantage is the relative usefulness of provider volume compared to other measures for operations that are infrequently performed. Many operations are not done often enough to generate the sample sizes needed to estimate precise mortality and morbidity rates for individual hospitals. This limitation is particularly important when considering the specific context where quality may be measured best using provider volume. For instance, the quality of uncommon operations with a strong volume-outcome effect, such as pancreatic resection and esophageal resection, may be most optimally measured using hospital or surgeon volume. Most hospitals perform only a few of these procedures each year, and directly measuring outcomes for these operations is therefore not possible.

The chief limitation of provider volume as a quality measures it that the relationship between volume and outcome only holds true on average [15]. Thus, provider volume does not work well for predicting the quality of individual hospitals or surgeons. For an operation that is performed often enough for mortality rates to provide precise estimates of mortality rates, such as coronary artery bypass grafting, this shortcoming is particularly evident. One recent study of coronary artery bypass surgery demonstrated that $85 \%$ of low-volume and $89 \%$ of medium-volume hospitals had mortality rates that were no different from the national average [16]. In addition, only $11 \%$ of high-volume hospitals had mortality rates that were statistically lower than the average. However, because hospitals perform hundreds of cases of coronary artery bypass each year, this may be the only operation where it is feasible to use risk-adjusted mortality rates to measure performance.

When considering the goal of quality improvement, another limitation of volume becomes apparent. In contrast to measuring outcomes or processes, volume is not actionable from the provider's perspective. When providers have poor outcomes or low rates of adherence to an important process of care, they can seek to correct the underlying problems. Any efforts to unnecessarily increase volume may result in more inappropriate operations, especially for more discretionary operations. From a patient and payer perspective, however, volume is actionable. Public reporting and pay-for-performance initiatives will direct patients toward better hospitals and result in a net reduction in mortality rates.

\section{Acknowledgments}

Dr. Justin Dimick was supported by a Veterans Affairs Special Fellowship Program in Outcomes Research. The views expressed herein do not necessarily represent the views of the Department of Veterans Affairs.

\section{References}

1. Halm EA, Lee C, Chassin MR. Is volume related to outcome in health care? A systematic review and methodologic critique of the literature. Ann. Intern. Med. 2002;137:511-520

2. Dudley RA, Johansen KL, Brand R, et al. Selective referral to highvolume hospitals: estimating potentially avoidable deaths. J.A.M.A. 2000;283:1159-1166 
3. Birkmeyer JD, Siewers AE, Finlayson EV, et al. Hospital volume and surgical mortality in the United States. N. Engl. J. Med. 2002;346:1128-1137

4. Birkmeyer JD, Dimick JB. Potential benefits of the 2003 Leapfrog standards: effect of process and outcomes measures. Surgery 2004;135:569-575

5. Khuri SF. Invited commentary: surgeons, not General Motors, should set standards for surgical care. Surgery 2001;130:429-431

6. Khuri SF, Daley J, Henderson W, et al. Relation of surgical volume to outcome in eight common operations: results from the VA Nationa Surgical Quality Improvement Program. Ann. Surg. 1999;230:414-429

7. Hannan EL, Kilburn H Jr, Bernard H, et al. Coronary artery bypass surgery: the relationship between inhospital mortality rate and surgical volume after controlling for clinical risk factors. Med. Care 1991;29:1094-1107

8. Edwards EB, Roberts JP, McBride MA, et al. The effect of the volume of procedures at transplantation centers on mortality after liver transplantation. N. Engl. J. Med 1999;341:2049-2053

9. Chen J, Radford MJ, Wang Y, et al. Do "America's Best Hospitals" perform better for acute myocardial infarction?. N. Engl. J. Med. 1999;340:286-292
10. Birkmeyer JD, Stukel TA, Siewers AE, et al. Surgeon volume and operative mortality in the United States. N. Engl. J. Med. 2003;349:2117-2127

11. AHRQ Quality Indicators-Guide to Inpatient Quality Indicators Quality of Care in Hospitals-Volume, Mortality, and Utilization, Rockville. MD, Agency for Healthcare Research and Quality, 2002, AHRQ pub. No. 02-R0204

12. Romano PS, Zhou H. Do well-publicized risk-adjusted outcomes reports affect hospital volume? Med. Care 2004;42367-42377

13. Marshall MN, Romano PS, Davies HT. How do we maximize the impact of the public reporting of quality of care?. J. Qual. Health Care 2004;16(Suppl 1):I57-I63

14. Marshall MN, Shekelle PG, Leatherman S, et al. The public release of performance data: what do we expect to gain? A review of the evidence. J.A.M.A. 2000;283:1866-1874

15. Birkmeyer JD, Dimick JB, Birkmeyer NJ. Measuring quality in surgery: structure, process, or outcomes?. J. Am. Coll. Surg. 2004;198:626-632

16. Rathore SS, Epstein AJ, Volpp KG, et al. Hospital coronary artery bypass graft surgery volume and patient mortality, 1998-2000. Ann Surg. 2004;239:110-117 